\title{
Less Ado, More Done: Verbal and Visual Antithesis in the Media
}

\author{
Hilde van Belle
}

KU Leuven / Thomas More

Faculteit Letteren / Text and Interpretation

Taal en Communicatie Antwerpen

Sint Andriesstraat 2

2000 Antwerpen

Belgium

hilde.vanbelle@arts.kuleuven.be

\begin{abstract}
The inventive, argumentative and stylistic possibilities generated by figures in general and the figure antithesis in particular are explored by Jeanne Fahnestock in the field of science. These ideas on the possibilities of antithesis are developed in the analysis of some cases of this figure in the media. This paper explores how antithesis can consist of textual and visual elements, and how various sorts and degrees of opposition are constructed in the figure.
\end{abstract}

Résumé: Jeanne Fahnestock explore dans le domaine de la science les possibilités inventives, argumentatives et stylistiques générées par les figures rhétoriques en général et la figure rhétorique de l'antithèse en particulier. Ces idées sur les possibilités de l'antithèse sont développées dans l'analyse de quelques cas de ces figures employées dans les médias. Cet article explore comment l'antithèse peut consister en éléments textuels et visuels, et comment différents types et degrés d'opposition sont construits dans la figure rhétorique.

Keywords: antithesis, figuration, media, visual antithesis

\section{Introduction}

The inventive, argumentative and stylistic possibilities generated by the figures are explored by Jeanne Fahnestock (1999) in the field of science. Especially antithesis, the juxtaposition of contrasting words or ideas, deserves our attention, as Aristotle attributes to it an important prototypical role at the very outset of an embryonic theory of figuration. This paper outlines Fahnestock's position on the importance of the antithesis figure within the general frame of functional figuration she finds in $\mathrm{Ar}-$ istotle's work.

These ideas on the possibilities of antithesis I will develop in an analysis of some cases of this figure in the media. Rhetori-

(C) Hilde van Belle. Informal Logic, Vol. 33, No. 3 (2013), pp. 343-360. 


\section{Hilde van Belle}

cians can study how various sorts and degrees of opposition are constructed in texts and how competing choices of oppositions are put to work, how traditional oppositions are forced into new ones, or how false antitheses are constructed (see also Govier). I will examine how textual and visual elements that form an antithesis interact, and how they are pushed into more, less, or a different opposition.

Whereas rhetorical elements such as elocutio and style figures often are studied within domains that focus rather on aesthetic appreciation, this analysis fits in the tradition that stresses the heuristic aspects of rhetoric and examines the argumentative function of figures. Since the original publication in 1958 of The New Rhetoric, A Treatise on Argumentation by Perelman and Olbrechts-Tyteca, rhetoricians have reconsidered the relation between style and argument in an attempt to undo the fragmentation of the rhetorical domain and to understand rhetoric in its fundamental dynamism and in diverse discourse types. This analysis presents Fahnstock's interpretation of Aristotle's work on antithesis, and elaborates these findings by introducing a new element to the discussion, namely the possible relations between textual and visual elements in contemporary examples of the antithesis figure.

\section{Figuration and antithesis}

In her work on figuration, Fahnestock observes how Aristotle mentions antithesis as one of the three basic figures to form a polished prose style, the other two being metaphor and energeia (figures aiming at vivid, lively description). Together, they are the three forms of asteia (sources of urbane expression) and as such they can serve as prototypes of the three well-known categories of style figures: metaphor for the tropes, antithesis for the figures of diction, and energeia for the figures of thought. This classification corresponds with three important linguistic categories that form the semantic, syntactic and pragmatic level of speech, the first focusing on term selection, the second on phrasing, and the third on speaker intentions. The three sources of asteia concern effective form devices, Fahnestock claims, and although Aristotle does not develop this classification of the figures as such, he definitely shows what they do, suggesting the mechanisms that make them work (Fahnestock 2000, p. 171).

Aristotle actually "suggests that certain devices are compelling because they map function onto form or perfectly epitomize certain patterns of thought or argument" (Fahnestock 1999, p. 26). Thus, he develops an implicit figuration theory that is not based on the problematic substitution principle but more inter-

(C) Hilde van Belle. Informal Logic, Vol. 33, No. 3 (2013), pp. 343-360. 
estingly on an iconic combination of form and function. The form/function discussion is an important paradigm in figuration theories that often suggest a clear distinction between the two. This shows for example in the tendency to focus on one of them: the more formal features a figure is attributed to, the less functional elements, and vice versa. This tendency might very well be the reason why figures that combine form and function, like antithesis, are to be found in so many different categories ( $\mathrm{p}$. 14).

The form/function discussion is furthermore often clouded by the value-added theories of the figures that have dominated in the rhetorical tradition. Figures are considered to add emotion, charm, force, vivacity or elegance. This supposed difference between unmarked and marked language has pushed the figures to the exclusive field of markers of the literary text, so that any possible other function got out of sight. But any idea of substitution immediately raises the question as to what the substitution is for and to what this possibility of ornament might mean, as it suggests that some ornamental layer could be filtered out from normal or non-figurative language. Whenever the function of figures is exclusively reduced to the adding of charm, beauty, emotion, etc., they are reduced to epiphenomenal and superficial phenomena and they end up in a museum of curiosities.

To Aristotle, however, rhetorical style should never attract attention to itself, and figures should function in the process of learning and rendering insight. He nowhere claims the figures to be emotional, ornamental, or epiphenomenal in any other way. Ornatus, the fourth style device, is nowhere introduced by him; (probably) his pupil Theophrastus first mentioned it. The only way to see figures in their full power, then, is by restoring their link with reasoning and argumentation.

A traditional lexicon for lines of argument disappeared together with the cognate notion of the figures as epitomes of those lines. Indeed, Aristotle's examples are nowhere to be detected in contemporary writing courses, and the idea that figures can be functional in the search for new arguments might raise an eyebrow or two. This notion of the generic skills of rhetoric conflicts with our ideas of spontaneity of invention based on complicated cognitive processes, and with the confinement of procedures of method and argument to the specific disciplines or professions. Yet the popularity of metaphor to generate analogical reasoning could be a starting point for the assumption that human reasoning can follow many more lines than analogy alone.

Fahnestock develops the idea that in Aristotelian stylistics, dialectic, and rhetoric, "antithesis is a consistent, and consistent-

(C) Hilde van Belle. Informal Logic, Vol. 33, No. 3 (2013), pp. 343-360. 
ly important, concept, at once a verbal, analytical, and persuasive device" (p. 53). Aristotle's antithesis is

a verbal structure that places contrasted or opposed terms in parallel or balanced cola or phrases. Parallel phrasing without opposed terms does not produce an antithesis, nor do opposed terms alone without strategic positioning in symmetrical phrasing. Instead, the figure antithesis, according to Aristotle, must meet both syntactic and semantic requirements. (pp. 46-47)

For example, Gorgias' antithesis "the stronger leads, the weaker follows" would lose its power if it were changed into "the stronger leads, and what the weaker often does is follow into her footsteps." And whereas the syntactic structure of "the weather is fine, the food is good" is perfectly symmetrical, there is no semantic opposition hence no antithesis.

The semantic base of the figure can be formed by "natural" pairs, commonly used pairs of opposites, and as such easily conceivable by the public. The use of one in the first half of the figure creates the expectation of its verbal partner in the second half. This effect on the audience seems to be an important aspect of antithesis. In his examples, Aristotle shows how antitheses are typically built on contraries like good and evil, love and hatred, further divided in those that admit intermediates and those that don't. Contradictions are possible as well: pairs of words that form exhaustive either/or alternatives. Finally, antitheses can be formed by correlatives, pairs that designate reciprocal or complementary relationships, like causeleffect, or sell/buy ( $\mathrm{p}$. 49).

The parallel syntax of antithesis supports the contrast not only in a visual but also in an aural way. This way, antithesis functions both to delight the ear and deliver an argument. Contradictions form antitheses easily because they invite repetition that brings about parallel phrases. The effect of the opposition is enhanced by the neutral background of the parallel syntax. There is no way to put Oscar Wilde's antithesis better than this: "There is only one thing in the world worse than being talked about, and that is not being talked about" (Wilde 1985, p. 6).

Fahnestock finds more evidence in Aristotle's work that shows how the verbal form, the figure antithesis, can be recognized as the epitome of an underlying topical reasoning. Thus it becomes possible to use the figure itself as a stylistic prompt or frame for purely verbal invention (pp. 51-52). In his treatment of the 28 lines of argument in Rhetoric Book II, Aristotle explains how one topos of demonstrative enthymemes is that from opposites. The characterization of this topos is clearly antithetical. In 
Topics, Aristotle explains in nicely constructed antitheses how speakers can lean on existing opinions, and how contrasted words can be useful in building premise/conclusion pairs (Book I, Chapter 10). In Book II, Chapter 7, Aristotle shows how pairs of semantic opposites can be combined to create either single or double antitheses, and how arguers can use them to test a position. Double antitheses can serve to build an argument; single antitheses can be used to build a refutatio (Fahnestock 2000, p. 177):

Good to friends and bad to enemies. (double)

Bad to friends and good to enemies. (double)

Good to friends and bad to friends.

Good to enemies and bad to enemies.

Good to friends and good to enemies.

Bad to friends and bad to enemies.

The double nature of antithesis as the verbal phrasing of a topical device got lost over the centuries, and its syntactic and semantic components fell apart. It melted into other verbal devices that juxtapose semantic oppositions like the oxymoron, or it became a generalized descriptor for a compositional style of balanced phrases that form pairs with or without semantic contrast. The Aristotelian concept that an argument can be invented through stylistic choices disappeared altogether (Fahnestock 1999, p. 58).

Yet the Aristotelian antithesis can be useful in the framing of arguments. Antithesis can be built with already accepted opposites in using the frame of the figure as a prompt to invent or construct arguments. But an arguer can also use the familiarity of accepted pairs and the parallel syntactic structure to create new contraries by pushing a new pair into opposition. Familiar pairs such as smart/stupid, exciting/dull, brave/cowardly, active/lazy, rational/irrational can easily be summed up and finally serve as the structure of an appreciation of certain groups: Italians are...while Greeks are..., men are...while women are..., etc. Furthermore, the nature of an existing opposition can be changed by antitheses: an existing opposition is shifted to a new one, either with the terms pushed further apart so that they mutually exclude each other, or with the terms set as the two poles on a connecting continuum. For example, the arguments of nationalist populist politicians often aim at widening the gap between groups or ideas, or creating new oppositions that suggest one can't belong to different groups: if you're a loyal Flemish (Andalusian, Texan) citizen, you can't be a loyal Belgian (Spanish, American) citizen.

(C) Hilde van Belle. Informal Logic, Vol. 33, No. 3 (2013), pp. 343-360. 
Fahnestock suggests some reasons why antithesis and metaphor grew apart over time. Metaphor was treated in Aristotle's more popular Poetics, while antithesis was to be found in the now neglected Topics. Also, metaphor traditionally is banned from argumentation situations, while antithesis is distrusted because of both its emotional strength and persuasive weakness, as it often sounds unnatural and too predictable. Work on metaphor is so popular because it allows scholars and researchers to believe they have a window on a fundamental, generative cognitive process, she claims. But the obsession with metaphor narrows down the much richer rhetorical tradition that provides for other possible conceptual and heuristic resources that are formally identifiable as well (Fahnestock 2000, pp. 181183). For instance, historical and actual debates that have sometimes been characterized by competing metaphors can also be described as competition between kinds of antithesis, starting from the question whether a particular pair of terms represents a mediated or unmediated opposition. The human/ape distinction, for instance, involving metaphors like primitive/civilized can also be studied from the perspective of the cut/scale opposition. One can very well look for the kind of evidence (like language/no language) that is stressed in the discussion, and in what kind of antithesis it is put (Fahnestock 1999, p. 75).

\section{Antithesis in multimodal media}

In the fifth and fourth century $\mathrm{BC}$, in a society where citizens had to defend their cases in court, antithesis was one of the more popular style figures. The ethos of the speakers-common people - had to be truthful, so they had to stay away from all too subtle nuances or poetical abundance. Our own popular mass media abound with polarisation and oppositions, often shaping the world into simple and compelling contrasts, suggesting the kind of pathos that allows no subtlety. As media communication has become increasingly multimodal, and as the availability of photo or video material often determines the news value in the newsroom, it makes sense to include the (audio-)visual aspects in the analysis of media material.

The art of rhetoric found its origin in the oratory; it considered not only the inventing and writing of speeches, but also their delivery. This means that it is in no way exclusively restricted to the verbal. The attention to speech delivery considers elements of voice and body language, viz., the audio-visual aspects of presentation. In fact, the oratory aspect of the Greek culture used to bring into play many senses of the auditorium: 
the showing of a scar or a bloody weapon could be an inherent part of a successful speech (Hobbs, p. 58).

The history of verbal versus pictorial communication is marked by conflict and subversion (see, e.g., Birdsell and Groarke, Goggin, Kress and Van Leeuwen 2006, Olson), but from its very beginning, the art of rhetoric did pay attention to vision and description. Translation of visual images into verbal text-and the other way around-were part of writing and speaking instruction; as described in the numerous ekphrasis (description) devices on the composition of vivid descriptions, on "bringing before the eyes" (Hobbs, p. 56). Quintilian saw visualisation as the most powerful means of arousing emotion, possibly the best way to convince an audience. Ekphrasis was a very popular issue in the Middle Ages, as well as the interaction between vision and memoria, i.e. the memorizing of a speech.

The popular Renaissance emblem books show how pictures and words are used next to each other in collections that served for entertainment, education, spiritual instruction and even memory aids. The link between image, imagination and rhetoric is explicit in Bacon's work, and the role of observation and imagination in its relation to knowledge and reason is discussed by most Enlightenment authors; most of them are also fascinated by the scientific aspects of vision and the constructed nature of human sight (p. 61).

Although rhetorical theory may have its roots in oral discourse, and may have focused upon verbal communication too easily, it has in no way explicitly excluded visual aspects of communication. The difference between linguistic and visual discourse is not in the least constitutive for the discipline of rhetoric.

Both words and images take part in the production of meaning, Kress and Van Leeuwen mention, and the ways in which meanings are mapped across different semiotic modes, are culturally and historically specific (Kress and Van Leeuwen 2006, p. 2). According to these authors, the traditional insistence on the monomodal - that favors for instance written text on a densely printed page - only reveals that this once was the most highly valued kind of writing. This status of the verbal is possibly one of the reasons why verbal texts are still very much considered to be standing on their own, and studied apart from other modalities, while most work on visual communication-apart from work on aesthetic appreciation - does not exclude the verbal.

As to the status of the verbal, the authors claim that the situation is now being reversed. Written text is less structured by linguistic means, and more by visual means, such as layout, spa-

(C) Hilde van Belle. Informal Logic, Vol. 33, No. 3 (2013), pp. 343-360. 
tial arrangement, and other graphic elements on the page. Texts are no longer "written," but "designed."

... writing may remain dominant, with the visual fulfilling a 'prosodic' role of highlighting important points and emphasizing structural connections. But it may also diminish in importance, with the message articulated primarily in the visual mode, and the words serving as commentary and elaboration. Visually and verbally expressed meanings may be each other's double and express the same meanings, or they may complement and extend each other, or even clash and conflict. (Kress and Van Leeuwen 1998, p. 187)

According to the authors, the skills of visual literacy are no longer reserved for specialists. By now, visual literacy has become a "matter of survival" for anyone (Kress and Van Leeuwen 2006 , p. 3). The shift away from the so-called purely verbal ideal towards the more hybrid modes actually revealed the fact that most communication is hybrid, and that the existence of either a purely verbal or purely visual mode is probably more of a rather abstract idea than a common human experience. Clearly, the changing practices force us to develop new modes of text analysis, where the visual and particularly the interplay between the verbal and the visual can be described adequately.

The increasing multimodality in our time consists mainly of the merging of the different modes into hybrid texts. This new situation does include the reshuffling of historical and intellectual status cards. Obviously, themes such as the differences between verbal or linguistic and visual communication, or the interdependence of physiological functions and thinking are beyond the scope of this paper. I will work in a tradition that does not put both fields in opposition, in an attempt to find out how the different angles can enrich analysis and interpretation.

Figures are not to be reduced to some superficial ornament, and if we want to know how they work and what they do, we should study and evaluate them in their proper context and function. For metaphor, the role and power of both verbal and visual images and imagination have long been acknowledged. Giving antithesis more weight and importance enhances the relation between lines of reasoning and style. Bringing back topical invention in the antithesis figure suggests how the more abstract human cognitive faculties like schemes of thought can be epitomized both visually and verbally. For antitheses in particular, both verbal and visual, we can determine whether they are single or double, what kinds of oppositions are at work, and whether certain lines of argument are epitomized. An analysis that tries to reconstruct the dynamism and evolution of opposi- 
tions within one artefact can show how graphic and verbal lines of argument can work together, interfere, or contradict; how words can generate images and vice versa.

I will study a few artefacts from the perspective of the antithesis figure. Inspired by the metaphor criticism Sonja Foss (2004b, pp. 299-331) proposes, I explore whether a similar kind of antithesis criticism could be possible. As I understand figures as functional elements and not as ornament, I will take into consideration the specific context that makes the figures work or not. I will explicitly look for the argument value they may have, and assess each example separately.

\section{Cases}

A first finding: the figure antithesis is not exactly ubiquitous in our news media. Striking antitheses, either verbal or visual or mixed, are rare. Apparently the old distrust about the figure for its unnatural and predictable character still holds. Moreover, the typical elliptic and concise style of newspaper headlines does not really allow for the explicit formal and extensive repetition of grammatical elements that enhance the contrast between the antithetical pairs.

Here are some examples of plain verbal antithesis: Tom Boonen needs help, not punishment. This is a single antithesis, because one element is combined with a contrasting pair (TB needs help / not punishment). Here is a double verbal antithesis: The world is doing badly, yet Dutch literature is thriving (The world / Dutch literature versus doing badly / thriving). The figure seems to be popular in movie comments like these: 'Sex' adds sheiks, loses chic and 'Prince of Persia': pretty to look at, a pain to watch. Often, it comes down to a catchy word play without any substance.

(1) Macbeth

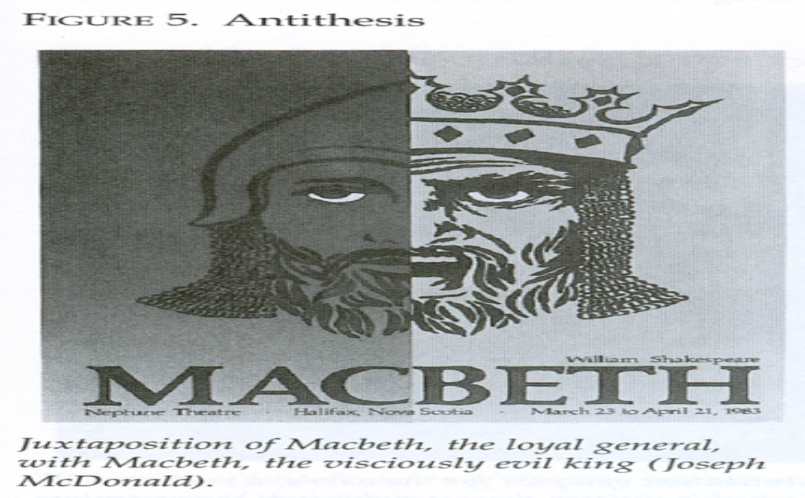

(C) Hilde van Belle. Informal Logic, Vol. 33, No. 3 (2013), pp. 343-360. 


\section{Hilde van Belle}

This Macbeth poster shows one verbal term in combination with two contrasting images. It is a result of an experiment by Hanno H.J. Ehses in which the heuristic possibilities of ten style figures are tried out. Students in a design class were asked to find graphic encodings for a poster that announces this Shakespearian tragedy, using the formal construction principle of a specific rhetorical figure as a guideline (Ehses, p. 173).

The poster shows shape and shade differences at either side of the vertical line to reveal two Macbeths, evoking two moments in the life of the main character in this drama. The two halves of the same face form the parallel construction, or the syntactical element the antithesis is based upon. The two sides of this poster show the younger loyal general and the older evil king he has become, introducing both a time element and the driving force of this character. The lines at the left side are in soft shades of grey, leaving one white element to stand out: the little white crescent in Macbeth's eyes, repeated at the right side, suggesting the one element that holds this character together: the fatal ambition to become king. Following the reading direction of the word, the picture should be read from the left to the right, the right side representing the older king in sharply contrasting black and white lines, suggesting his cruelty.

This is a single antithesis: the word Macbeth is yoked with two visual opposites. The verbal element Macbeth is supported visually by the image of the face, and the contrast is expressed only visually. The two white crescent shapes in Macbeth's eyes form a striking repetitive element within the visual antithesis. As suggested by Aristotle (and interpreted by Fahnestock), single antitheses are not suitable for building a new argument, but they can serve as a refutation (Fahnestock 2000, p. 177). Indeed, for those who are familiar with the theme, this antithesis reveals the dramatic value of the play, and shows Macbeth as a tragic hero, driven to death by his ambition. The antithesis works nicely: by opposing the younger and the older Macbeth, it raises the general question: what made this man change from a young and eager general into an old and desperate king? For those who don't know the play, the antithesis works as well, but at a lesser intensity: presumably the person depicted is a soldier who becomes an angry or wicked king. In any case, a certain incompatibility, some kind of contrast is revealed, suggesting the tragic events in the play. The line of argument can be reconstructed as such: Macbeth is a tragic hero / because from the young and eager general Macbeth he changed into the old and desperate king Macbeth.

This technique is applied in many commercials as well. The brand name is the unifying factor, the contrast is shown visually, and the underlying reasoning is something along the lines 
of If you drink Danone, you'll lose weight; if you don't, you'll stay fat. / If you don't drink Coca Cola, you'll stay lonely; if you do, you'll become popular. Those combinations are interesting for advertising, seeing as such antitheses have a simplifying effect and make the consumer forget all about the grey middle zone of intermediate processes and positions. The combination of one word or slogan with a pair of contrasting pictures often creates a striking or funny effect: a question, a joke, a surprise, a riddle, a problem. Sometimes, the line of argument created can serve as a refutation, for instance in cartoons where the pretended impossible combinations in the lives or characters of celebrities are condemned. Imagine for example a cartoon that shows president Obama in a western outfit on one side and in a Muslim outfit on the other, with a caption that says "Obama's lies."

My suggestion is that the argument line of those "easy" antitheses often comes close to what Perelman and OlbrechtsTyteca coined quasi-logical arguments, where incompatibilities are presented as if they were logical contradictions. But this is definitely not always the case. In all of these examples, the claim is presented verbally, and the reasons visually — within the antithesis.

Another technique that is very widespread goes the other way around: in this next example, the image of the politician forms the visual element, while the verbal antithesis- "less ado, more done"-is showing her message. Here, the repetition of the verb 'to do' results in a somewhat stronger effect. A similar example is a picture of a flashy car accompanied by the words: More car for less money. The line of argument is similar to examples one and two:

(2) Less ado, more done.

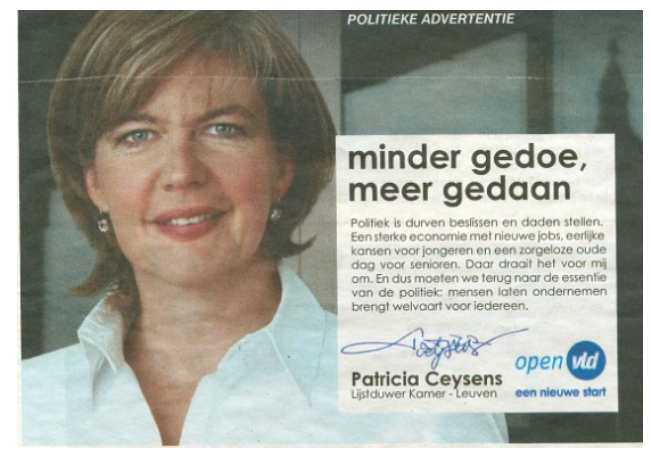

the surprise effect prevails. Another example is a bit more complicated, as it shows the visual conclusion of a sad message Last year flowers, this year nothing. In this Secretary's Day drama, 


\section{Hilde van Belle}

we see the picture of a sad looking secretary, presenting the reasons of her sorrow in a verbal antithesis. In these examples, the conclusion is presented visually (vote for me / buy this car / I'm $s a d)$, and the reasons verbally_-within the antithesis.

\section{(3) Chat with politicians}

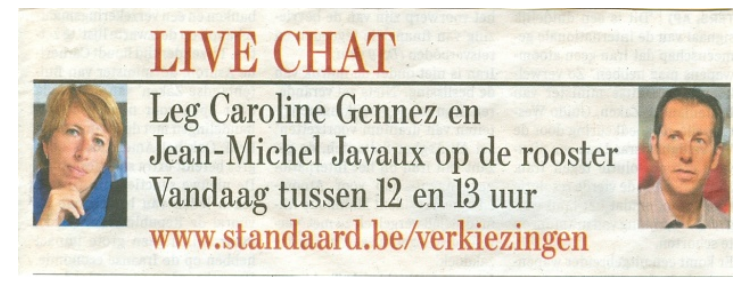

In this text, the verbal message that invites us to go to the newspaper's elections page and "Challenge Caroline Gennez and Jean-Michel Javaux today between noon and 1:00 p.m." is imperative, but the visual presentation suggests contrast rather than comradeship between these politicians, as it pushes them apart to the far sides of the message. The visual separation of the two politicians widens the gap between them, while in the verbal message there is no contrast between them whatsoever. Is this a functional antithesis? No, it is only a visual suggestion of opposition, a very popular technique in the media-and not only there- that suggests the way politics work.

(4) Johannesburg public transport police

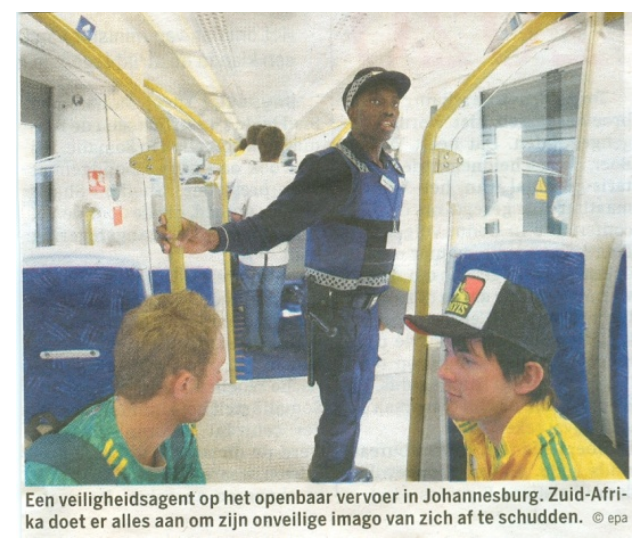

This image shows a strong visual contrast with the two (white) boys and the yellow bars separating them from the aisle in the middle, where a (black) man in uniform is prominently present, keeping law and order. The verbal message at the bottom of the picture reads as follows: Security officer on the public transportation in Johannesburg. South Africa is doing its utmost best to get rid of its unsafe image. 
The formal contrast is visual, not verbal. One can easily understand the paradigmatic visual message of the policeman doing his job and taking the middle position between two boys at the sides of the picture. The claim that The boys will remain safe is backed by the argument that there is a police officer who prevents violence. It is a concrete example of the more general verbal pragmatic argument that presents as claim that South Africa wants to get rid of its bad image, supported by the argument that South Africa has put policemen on public transport.

The visual interpretation of the text adds contrasting elements to it, and as such this example is similar to example 3 . In this example, however, there is some argumentation, but again no antithesis. Interestingly, the visual contrast between the policeman and the boys is presented as the intended situation of safety, attributing a central position to the policeman as the incarnation of law and order and stressing the triangular arrangement of the three figures. This suggestion of a peaceful South African society is even enhanced by the visual contrast between the black protective policeman and the white boys. As a whole, the picture simply supports the argument, and the suggested visual contrasts appear to work towards an idea of harmony rather than opposition.

(5) Lake levels sink, state fears rise (The Detroit News, June 12, 2007)

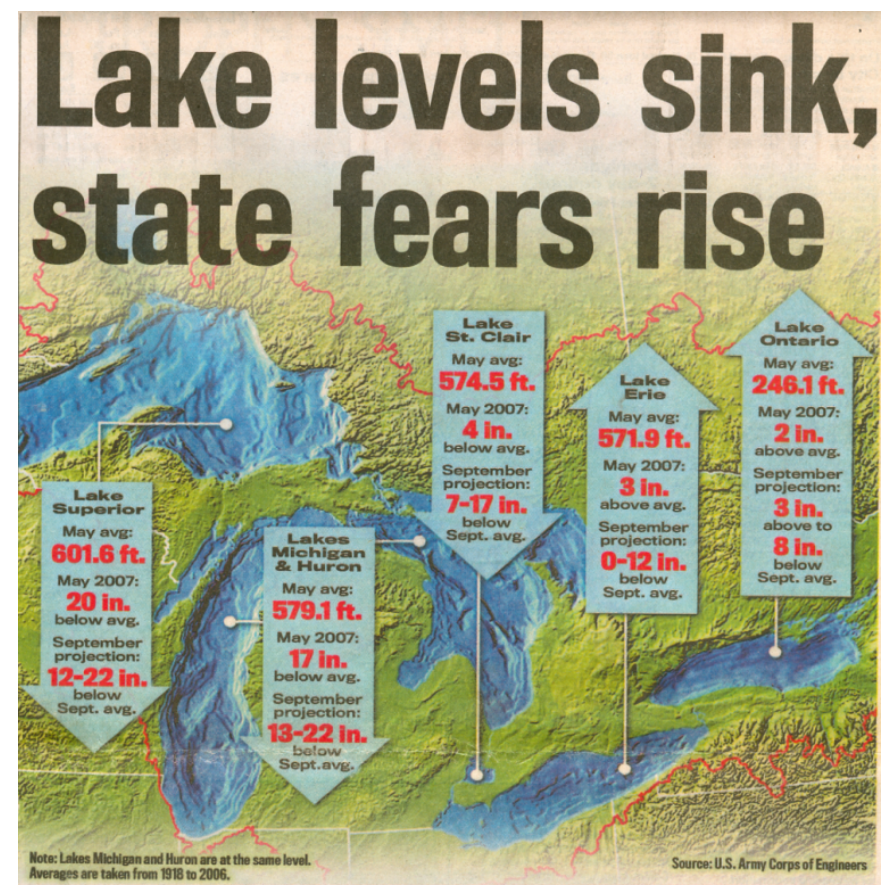

(C) Hilde van Belle. Informal Logic, Vol. 33, No. 3 (2013), pp. 343-360. 


\section{Hilde van Belle}

The verbal antithesis is constructed from two pairs: the familiar sink / rise contraries and the more surprising lake level / state fears pair. The two parts of the sentence show a causal relationship between the sinking levels and the rising fears, but the picture shows a far more complex entity. In the background we see a photographic air view of the lake region, filled in with five up or down vectors that in their turn present data about the water level of the five lakes. The very dominant vectors suggest a repetition of the verbal sink / rise contrast, but as some lake levels appear to rise and others to sink, they actually create a confusing up-and-down effect.

In this case, the verbal message and its visual counterpart clearly inspired one another, but the argument is not clear at all. This "antithesis" comes down to a formal play, where the verbal and visual oppositions between sink and rise are structuring a message that is far too complex to be put down in an antithesis.

\section{(6) Science versus Ait Oud}

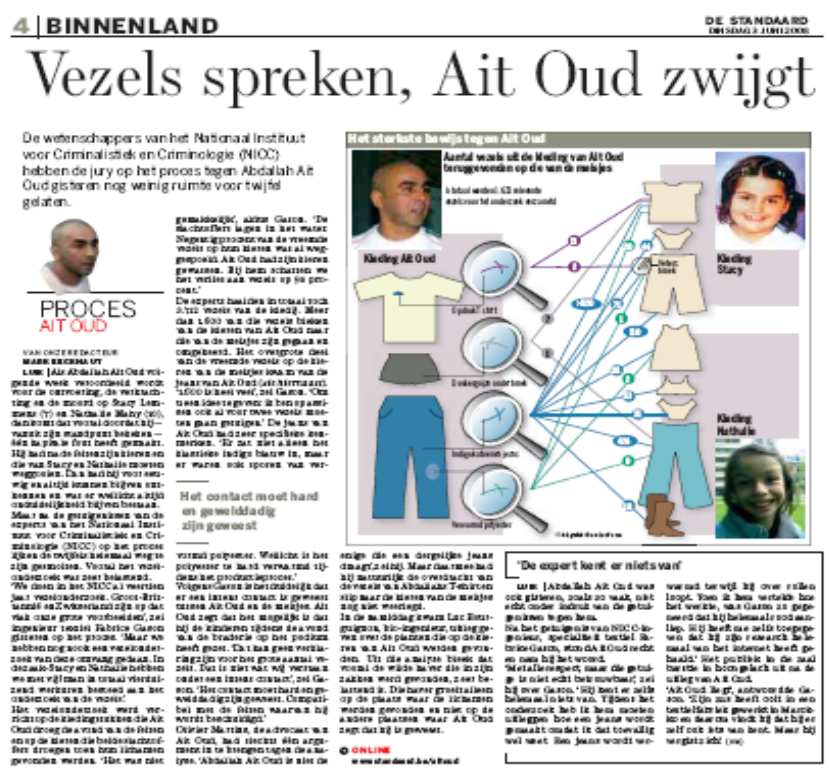

This example shows a catchy antithesis in the title and a vibrant and fascinating illustration. "Speaking" scientific evidence is put against the silence of the accused-whose name is Ait Oud - who by this silence keeps denying the facts. Vezels spreken, Ait Oud zwijgt (Fibres talk, Ait Oud keeps silent). The double pair the antithesis is built upon consists of the obvious speaking versus keeping silent contraries on the one hand, and the fibres versus their previous owner-Ait Oud wore the clothes - on the other. Although the fibres talk, AO keeps silent. It creates an opposition between the overwhelming scientific evidence (which is the entity the fibres stand for) and the ac- 
cused stubbornly denying the murders. It expresses the choice the public is confronted with, and the boundaries of scientific evidence in the domain of jurisdiction. This antithesis, within this context, is an example of a style choice that epitomizes an important question and stimulates public debate. Claim: It is unclear which source we are to believe in the case of AO. Reason: Science proves AO guilty, while AO denies his guilt.

The illustration shows a picture both of the (silent) AO, and of his clothing, with the abundantly 'talking' fibres. Some 20 vectors leave his garments and head for the clothes of the two raped and murdered children, at the right side of the picture. The visual effect is outspoken, as well as the title message of the picture: The strongest evidence against Ait Oud. This picture clearly backs the overwhelming scientific evidence of the fibre examinations: the fibres speak. The left-right opposition and the little pictures showing the faces of the three parties add to the narrative aspect of the illustration, suggesting the cruel rape and murder act of the accused (left). The illustration creates a new pair: it is the opposition between the accused AO (left side) and the two victims (right side). It can easily be considered a subargument for the first part of the antithesis: the fibres prove his guilt and the picture as a whole evokes his cruel deeds.

The cartoon on the next page starts from a (verbal) question, provides us with an enigmatic verbal answer, while the final explanation of the answer is to be found in the picture. This picture provokes a clear and convincing antithetical line of reasoning: if the train goes to the right, the safest side is on the left (with a soft landing promised to the two gentleman, and no great injuries to the big lady), if the train goes to the left, the safest side is on the right (with dramatic consequences for the gentlemen). Here, the visual contrast between the two tiny men on the one side of the train compartment and the big lady on the other side is enhanced by the line of hypothetical reasoning that is generated by the verbal message. Claim: The safest side in a train depends on the direction of the train (verbal) and the weight of the victims (visual). Reason: if the train goes into the direction of weighty people, it is safe; if the train goes into the direction of small people, it is unsafe. The visual adds the element of body weight to the verbal element of direction, and that is what creates the pun. 
358 Hilde van Belle

(7) The safest side in a train crash

Which is the safest side in a train crash? / That depends entirely on the direction of the train.

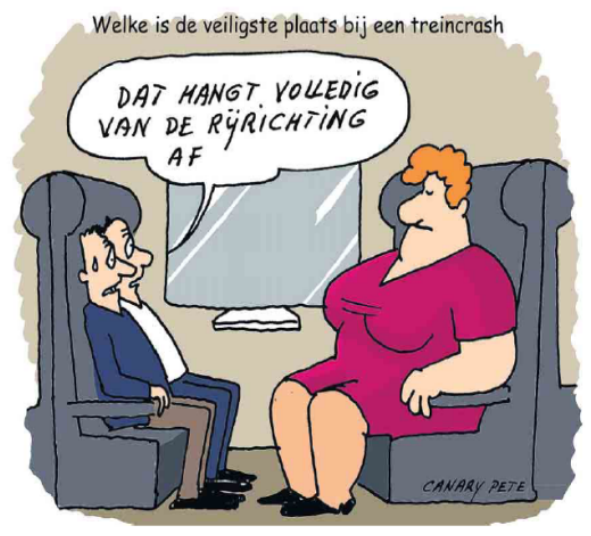

\section{Conclusion}

Perelman and Olbrechts-Tyteca stated that an effective rhetorical figure cannot be recognized as such without considering its context and function. In the cases analysed, we can see that some contrasts are verbal, others visual; sometimes they repeat one another; often the verbal and visual complement one another to reveal the full meaning. Some cases, like Macbeth (1) and Less ado, more done (2) are quite simple. Their visual impact is strong, but their functional value is often limited to a suggestion of surprise. In those cases, the reasoning is in the antithesis, no matter whether these premises are verbal or visual; and the conclusion is within the single term yoked to the contrasting pair, no matter whether this term is visual (picture of politician) or verbal (Macbeth). Sometimes the visual element creates an opposition that is not present in the words, adding new elements but not creating an antithesis (3. Chat with politicians / 4. Johannesburg). Example 5 (Lake levels sink, state fears rise) shows how both a verbal and a visual 'antithesis' are nothing more than a formal game, and in example 6 (Fibres talk, Ait Oud keeps silent) we see how the illustration supports one side of the opposition between science and the suspect that is expressed in the verbal antithesis. Example 7 (train crash) shows quite a complex and dynamic interplay between the verbal and the visual elements of a witty antithesis.

From these few examples, we can draw the tentative conclusion that functional verbal/visual antitheses are rare, and that 
often, the evocation of oppositions comes down to a play of words and/or forms without any clear line of reasoning. Sometimes, however, interesting antitheses are formed, and in those cases it makes sense to examine how form and function support and create one another, and how different kinds of contrasts are made to work in argumentative moves. Adding the visual aspect to the analysis of antitheses provides us more insight into the way both verbal and visual elements can help to construct a rhetorical figure in its full power. ${ }^{1}$

\section{References}

Aristoteles (2004). Retorica [transl. Marc Huys], Groningen: Historische uitgeverij.

Birdsell, D.S. \& L. Groarke (2004). Toward a theory of visual argument. In C. Handa (Ed.), Visual rhetoric in a digital world. A critical sourcebook, pp. 309-320. Boston/New York: Bedford/St. Martin's.

Blair, J.A. (2004). The possibility and actuality of visual arguments. In C. Handa (Ed.), Visual rhetoric in a digital world. A critical sourcebook, pp. 344-363. Boston/New York: Bedford/St. Martin's.

Ehses, H.J. (2004). Representing Macbeth: A Case Study in visual rhetoric. In C. Handa (Ed.), Visual rhetoric in a digital world. A critical sourcebook, pp. 164-176. Boston/ New York: Bedford/St. Martin's.

Fahnestock, J. (1999). Rhetorical figures in science. New York/Oxford: Oxford University Press.

Fahnestock, J. (2000). Aristotle and theories of figuration. In: A.G. Gross, \& A.E. Walzer (Eds.), Rereading Aristotle's Rhetoric, pp. 166-184. Carbondale: Southern Illinois University Press.

Foss, S.K. (2004a). Framing the study of visual rhetoric: Toward a transformation of rhetorical theory. In C.A. Hill \& $\mathrm{M}$. Helmers (Eds.), Defining Visual Rhetorics, pp. 303-313. Mahwah, NJ / London: Lawrence Erlbaum.

Foss, S.K. (2004b). Rhetorical Criticism. Exploration \& practice. Long Grove, IL: Waveland Press.

\footnotetext{
${ }^{1}$ Parts of this paper were presented at the 2009 OSSA-conference Argument Cultures in Windsor, ON, Canada and the 2010 ISSA-conference in Amsterdam, The Netherlands. I thank the participants for their inspiring questions and comments.
}

(C) Hilde van Belle. Informal Logic, Vol. 33, No. 3 (2013), pp. 343-360. 
360 Hilde van Belle

Goggin, M.D. (2004). Visual rhetoric in pens of steel and inks of silk: Challenging the great visual/verbal divide. In C.A. Hill \& M. Helmers (Eds.), Defining Visual Rhetorics, pp. 87-110. Mahwah, NJ/London: Lawrence Erlbaum.

Govier, T. (2007). Two is a small number: False dichotomies revisited. In H.V. Hansen, C.W. Tindale, J.A. Blair, R.H. Johnson \& D.M. Godden (Eds.), Dissensus and the Search for Common Ground. CD-ROM, Windsor, ON: OSSA.

Hobbs, C.L. (2004). Learning from the past: Verbal and visual literacy in early modern rhetoric and writing pedagogy. In $\mathrm{C}$. Handa (Ed.), Visual rhetoric in a digital world. A critical sourcebook, pp. 55-70. Boston / New York: Bedford/St. Martin's.

Kress, G. \& Th. Van Leeuwen (1998). Front pages: The critical analysis of newspaper layout. In A. Bell \& P. Garrett (Eds.), Approaches to media discourse, pp. 186-219. Oxford/Malden, MA: Blackwell Publishers.

Kress, G. \& Th. Van Leeuwen (2006). Reading Images, The Grammar of Visual Design. London/New York: Rout-ledge.

Olson, Lester (2007). Intellectual and conceptual resources for visual rhetoric: A re-examination of scholarship since 1950. Review of Communication, 7: 1-20.

Perelman, Ch. \& Olbrechts-Tyteca, L. (1969). The New Rhetoric, A Treatise on Argumentation. [Transl. John Wilkinson \&Purcell Weaver]. London/Notre Dame: University of Notre Dame Press.

Wilde, O. (1985). The picture of Dorian Gray. London: Penguin. 